\title{
Prediction of adsorption efficiencies of Ni (II) in aqueous solutions with perlite via artificial neural networks
}

\author{
Sinan Mehmet Turp \\ Bitlis Eren University, Turkey \\ Faculty of Architecture and Engineering, Department of Environmental Engineering \\ ${ }^{*}$ Corresponding author's e-mail: smturp@gmail.com
}

Keywords: wastewater, treatment efficiency, adsorption, perlite, artificial neural network.

\begin{abstract}
This study investigates the estimated adsorption efficiency of artificial Nickel (II) ions with perlite in an aqueous solution using artificial neural networks, based on 140 experimental data sets. Prediction using artificial neural networks is performed by enhancing the adsorption efficiency with the use of Nickel (II) ions, with the initial concentrations ranging from $0.1 \mathrm{mg} / \mathrm{L}$ to $10 \mathrm{mg} / \mathrm{L}$, the adsorbent dosage ranging from $0.1 \mathrm{mg}$ to $2 \mathrm{mg}$, and the varying time of effect ranging from 5 to 30 mins. This study presents an artificial neural network that predicts the adsorption efficiency of Nickel (II) ions with perlite. The best algorithm is determined as a quasi-Newton back-propagation algorithm. The performance of the artificial neural network is determined by coefficient determination $\left(\mathrm{R}^{2}\right)$, and its architecture is 3-12-1. The prediction shows that there is an outstanding relationship between the experimental data and the predicted values.
\end{abstract}

\section{Introduction}

One of the major problems occurring in wastewater is the extensive amount of pollution. These waters are formed by the leakage of snow and moisture in waste materials held in storage sites. High need for oxygen and heavy metal content of the wastewater cause the quality of the receiving environment to deteriorate in the long term. These problems lead to toxic and anaerobic conditions in the receiving environment, fish death or exposition to pollution, and deterioration in water quality when the receiving environment is used as a water supply. Therefore, wastewater must be collected before it reaches underground and surface water resources, and should be treated appropriately. The main chemical methods used for treating wastewater are coagulation-flocculation, chemical deposition and chemical-electrochemical oxidation. Vivek et al. (2014) investigated the physical, chemical and biological methods that exist for the treatment of wastewater. It is generally difficult to ensure satisfactory treatment efficiency and a high quality outflow of water by using only a single method.

Nadaroglu et al. (2014) studied the removal of copper from aqueous solutions by using micritic limestone. They found that the maximum adsorption capacity was $237.05 \mathrm{mg} / \mathrm{g}$ for 1 hour and $1 \mathrm{~g}$ dosage. The experimental investigation results show that powdered micritic limestone has a high level of adsorption capacity in terms of copper ions. Adsorption data was correlated with the Langmuir and Freundlich isotherm models. It was found that the Langmuir and Freundlich isotherms fitted well with the data. Consequently, it was determined that powdered micritic limestone can be used successfully for removing copper ions from aqueous solutions.

Moradi et al. studied the adsorption of ammonium ions onto pumice as a natural and low-cost adsorbent. They found the optimum conditions for maximum removal of $\mathrm{NH}_{4}^{+}(70.3 \%)$ were found to be $100 \mathrm{~g}, 20 \mathrm{mg} / \mathrm{L}, 300 \mathrm{rpm}$ and $180 \mathrm{~min}$, for pumice dosage, initial $\mathrm{NH}_{4}^{+}$ion concentration, mixing rate and contact time.

For this, a combination of physical, chemical and biological methods is most commonly used. Garcia et al. (2014) explained that the most common physical methods used for the treatment of wastewater are precipitation, refining with air conditioning, adsorption and membrane filtration. In wastewaters containing heavy metals, refining is performed by using many different adsorbent materials. Malkoc et al. (2006) suggested that one such material is tea waste from the fixed bed column used for removing Nickel (II) from an aqueous solution. Different initial nickel concentrations are input concentrations used in this study. The result obtained show that the adsorbent material obtained from tea factory waste is efficient, and it is not an expensive material with regard to Nickel (II) removal. In addition, Erdogan et al. (2005) investigated the degree of nickel adsorption with activated carbon formed by waste peaches. The waste peaches in which the chemical activation with $\mathrm{K}_{2} \mathrm{CO}_{3}$ is performed are transformed into carbon. In the experimental study using this adsorbent material, 40-100\% adsorption capacities were obtained.

Alkan et al. (2001) studied the performance of a perlite adsorbent. Copper (II) ions in different aqueous solutions were studied experimentally in terms of different $\mathrm{pH}$ ranges, ionic 
strengths and temperatures. It was reported that a relatively high degree of efficiency is obtained using the expanded perlite.

The concept of artificial neural networks (ANN) emerged from using numerical computers to imitate the working principles of the human brain. The first studies were focused on the mathematical estimation of neurons. Studies have shown that neurons exchange information with neighboring neurons. Today, ANN is applied to many scientific fields. As in other fields, this approach is also used to obtain constantly improved results in environmental engineering disciplines. Treatment in terms of membrane processes is composed of complex relationships having non-linear and complex parameters. Such problems can be solved by using ANN effectively. In their studies, Bui et al. (2016) made extensive use of a multilayered feed-forward network with a back propagation algorithm. Podder et al. (2016) explained that the field referred to as ANN is a combination of these neurons in a certain form. ANN studies, with their nonalgorithmic, parallel and distributed computing capabilities, are different from conventional studies. With these different features, ANN can undertake complex and non-linear calculations easily and quickly. ANN, which is not algorithmic and cannot be used for very intense parallel computing, leads to new perspectives in computations involving learning ability and parallel distributed memory. Input layer neurons take the input data, transmit it to the next data processing layer through various links. This process continues until the data reaches the output layer. Sarkana et al. (2015) investigated the network formed involving oneway information flow. This is known as a feed-forward neural network. Prakash et al. (2008) estimated the efficiency of ANN in terms of Copper (II) biosorption. They used chips from mango trees as adsorbents. In this study, input concentration was used as input data for $\mathrm{ANN}$, and 4 different inputs in terms of temperature and particle size were used. The efficiency of biosorption is shown as an ANN output. Hammed et al. (2004) developed an estimation of the performance of wastewater refining plants in Cairo by using ANN. Maged et al. (2004) estimated two output concentrations in the form of biochemical oxygen demand (BOD) and suspended solid materials. For 10 months, BOD and suspended solid measurements were improved by training the experimental data every day using ANN. In addition, Bui et al. (2016) predicted the coagulation capacity of reactive dyed wastewater by applying chitosan. The ANN architecture in this study was formed in terms of a three-layer feed-forward ANN, and the coagulation processes, with a determination coefficient $\mathrm{R}^{2}$ showed a value of 0.986 .

Yesilnacar et al. (2012) studied a strong means of predicting the sulfate and sodium adsorption ratio (SAR) values in 24 observation wells of the Harran Plain. This study provides the first optimization of ANN architecture in terms of predicting sulfate and SAR values in groundwater. Moreover, Yesilnacar et al. (2008) proved that nitrate can be easily predicted with the help of a specifically designed, trained and validated neural network model. The developed model provided an acceptable fit to the experimentally obtained nitrate data in the 24 observation wells in the Harran Plain.

The application of neural networks for the purpose of estimating sorption isotherms is presented in the study described in the current paper. In this study, using measures of removal efficiency gathered through laboratory experiments and with regard to related variables such as the amount of adsorption, and the initial concentration and contact time, the prediction of removal efficiency is calculated and verified using the mean square error (MSE) and coefficient determination $\left(\mathrm{R}^{2}\right)$ functions of MATLAB artificial neural networks (ANN). The results of the study indicate a high correlation between the experimental data and the predicted data. In this section, a literature review and the aim of the study are briefly presented.

\section{Materials and Methods}

\section{Materials}

In this study the following materials were used: aqueous solutions were prepared in different amounts by dissolving $\mathrm{NiCl}_{2} \cdot 6 \mathrm{H}_{2} \mathrm{O}$ in distilled water, and $\mathrm{HCl}$ and $\mathrm{NaOH}$ solutions were used to adjust the $\mathrm{pH}$. Distilled water was extracted from TKA-Pacific (TKA-Wasseraufbereitungssysteme). The $\mathrm{pH}$ meter was calibrated with $\mathrm{pH} 4$ and $\mathrm{pH} 7$ buffer solutions (Merck, Darmstadt, Germany). The perlite, whose physical properties are given in Table 1, was obtained from the region of Balikesir-Turkey.

Table 1. Physical properties of perlite

\begin{tabular}{|c|c|}
\hline $\mathrm{pH}$ & $6.6-8.1$ \\
\hline Density & $35-410 \mathrm{~kg} / \mathrm{m}^{3}$ \\
\hline Specific gravity & $2.2-2.4$ \\
\hline Softening point & $690-1052^{\circ} \mathrm{C}$ \\
\hline Melting point & $1250-1253^{\circ} \mathrm{C}$ \\
\hline Specific heat & $395 \mathrm{~J} / \mathrm{kgK}$ \\
\hline Thermal conductivity at $24^{\circ} \mathrm{C}$ & $0.032-0.076 \mathrm{~W} / \mathrm{mK}$ \\
\hline$\%$ Retention of water & $36-55$ \\
\hline
\end{tabular}

\section{Effect of $\mathrm{pH}$}

$\mathrm{pH}$ has an important effect on the adsorption of aqueous solutions. It controls the adsorption of heavy metals in the solid-liquid phase. It also regulates the mobility of metal ions in aqueous solutions. Sasha et al. (2016) studied the strong force that pushes hydrogen ions away from metal ions. The $\mathrm{pH}$ interval in this study was 2.0 10.0. The removal of Nickel (II) ions by perlite is more efficient as the $\mathrm{pH}$ increases. The experiments were conducted with a minimum $\mathrm{pH}$ of 2.0 and a maximum $\mathrm{pH}$ of 10.0. However, the removal efficiency of Nickel (II) decreased in the $\mathrm{pH}$ interval 6.5 to 10.0 . The maximum efficiency in terms of the removal of Nickel (II) occurred at $\mathrm{pH} 4.5-5$. In accordance with these data, the study was conducted in terms of a $\mathrm{pH}$ interval of 4.5 to 5 . The $\mathrm{pH}$ parameter was not taken as entry data in ANN.

\section{Methods}

The experiments were conducted in the Department of Environmental Engineering Laboratory in which ambient temperatures were $25^{\circ} \mathrm{C}$. Single types of artificial aqueous solution were prepared in different concentrations. The details are explained in the section on experimental methods.

In this ANN study, MATLAB mathematical software was also used to predict the adsorption efficiency. One hundred and twenty experimental sets were used to develop the ANN.

\section{Experimental Methods}

Experiments were prepared using $500 \mathrm{ml}$ Erlenmeyer flasks with Nickel (II) artificial aqueous solutions. Metal solutions 
were prepared by dissolving appropriate amounts of $\mathrm{NiCl}_{2} \cdot 6 \mathrm{H}_{2} \mathrm{O}$ in distilled water. The necessary amounts of perlite were added and shaken for different periods

of time, 5-10-20-30 minutes respectively, in a shaker at $120 \mathrm{rpm}$ and an optimum $\mathrm{pH}$ of 4 to 5 . The experiments were repeated for different amounts of perlite $(0.1,0.2,0.5,1.0$, $2.0 \mathrm{mg}$ ). The initial Nickel (II) concentrations were $0.1 \mathrm{mg} / \mathrm{L}$, $0.2 \mathrm{mg} / \mathrm{L}, 0.5 \mathrm{mg} / \mathrm{L}, 1.0 \mathrm{mg} / \mathrm{L}, 2.0 \mathrm{mg} / \mathrm{L}, 5.0 \mathrm{mg} / \mathrm{L}$, and $10.0 \mathrm{mg} / \mathrm{L}$.

At the end of the experiment, the aqueous solutions in the flasks were filtered from the perlite with a vacuum pump in order to analyze the Nickel (II) concentration by using an Atomic Absorption Flame Emission Spectrophotometer (Shimadzu AA-6200).

\section{Artificial Neural Networks (ANN)}

In this study, a 3-layer feed-forward neural network is shown in Fig. 1.

The ANN architecture used in this study consists of input, hidden and output layers. Each layer is composed of many neurons that are connected to each other through weights. The connection type and neuron number in each section vary. No connections are allowed between the neurons in the same section. At the beginning of this training process, weight values between the connections were assigned randomly. The training algorithm changes the weight values of each iteration until the training is successfully completed. The most commonly used training algorithms are briefly mentioned below:

- The Levenberg-Marquardt (LM) algorithm is represented as the sum of the squares of linear functions.
It is an approximation of Newton's method that finds the minimum of a function. LM requires a great deal of memory space in order to successfully train the network (trainlm).

- The Conjugate Gradient (CG) is considered as a balanced algorithm which guarantees convergence to a local minimum of the second-order function. It does not need calculation of the second derivatives. After a certain number of iterations, the $\mathrm{CG}$ algorithm gives close results to a local minimum of the second-order function. CGF (Fletcher-Powell Conjugate Gradient) is a particular type of this algorithm (traincgb, traincgf).

- The most successful Quasi-Newton method is the Broyden, Fletcher, Goldfarb, and Shanno (BFGS) algorithm. However, there is a minor difference between the two algorithms. The BFGS scheme updates an approximate Hessian matrix by Taylor expansion on iteration of the algorithm. The BFGS also requires a memory-consuming process (trainbfg).

- The Scaled-Conjugate Gradient (SCG) algorithm, which differs from other conjugate gradient algorithms given by Hagan et al. (2003), typically uses a nonlinear search technique. This means that the computations are decreased in a single epoch (trainscg).

- The Gradient Descent algorithm (GDX) is an improved algorithm incorporating an adaptive learning ability and momentum for a better performance index. The momentum allows the network to respond to both local gradients and recent trends in the error surface, while

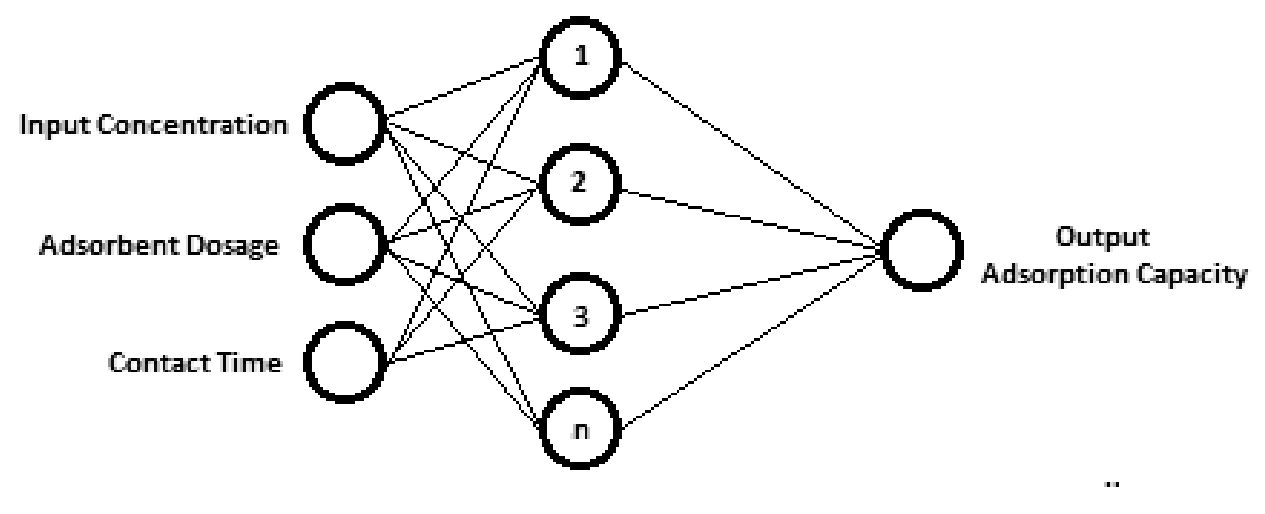

Hidden Layer

Fig. 1. Typical 3-layer feed-forward ANN architecture

Table 2. Comparison of algorithms for predicting output concentration (neuron number was 12)

\begin{tabular}{|c|c|c|c|}
\hline Algorithms & $\mathrm{R}_{2}$ & Mean Square Error & Iteration Number \\
\hline Traingdm & 0.893 & 0.17859 & 55 \\
\hline Traincgb & 0.865 & 0.16892 & 28 \\
\hline Traincgp & 0.926 & 0.03255 & 62 \\
\hline Trainlm & 0.924 & 0.03944 & 14 \\
\hline Traincgf & 0.894 & 0.19686 & 36 \\
\hline Trainbfg & 0.994 & 0.00018 & 39 \\
\hline Trainscg & 0.892 & 0.17543 & 38 \\
\hline
\end{tabular}


the small features in the error surface are disregarded (traingd, traingdm).

In order to determine the most suitable training algorithm, the algorithms described above were compared. For the training algorithms, a three layer ANN with a tangent sigmoid function (tansig) with 12 neurons and a linear transfer function as an output layer, was used.

The highest values in terms of coefficient determination $\left(\mathrm{R}^{2}=0.994\right)$ were gained using the BFGS quasi-Newton backpropagation algorithm (trainbfg) as shown in Table 2. The optimal results were obtained using the traincgf and trainlm functions, respectively. Other functions such as the Conjugate Gradient algorithm, the Gradient Descent algorithm and the Scaled-Conjugate Gradient algorithm, were also applied as training algorithms. Because the BFGS Quasi-Newton has a number of advantages over the other algorithms, this algorithm is used as a training function (trainbfg).

\section{Results and Discussion}

\section{Extraction of Data}

Experiments were conducted by obtaining output concentrations using Atomic Absorption Spectrophotometry in laboratory conditions by forming artificial wastewater in various concentrations for different contact times and different adsorbent dosages. The wastewater input concentrations

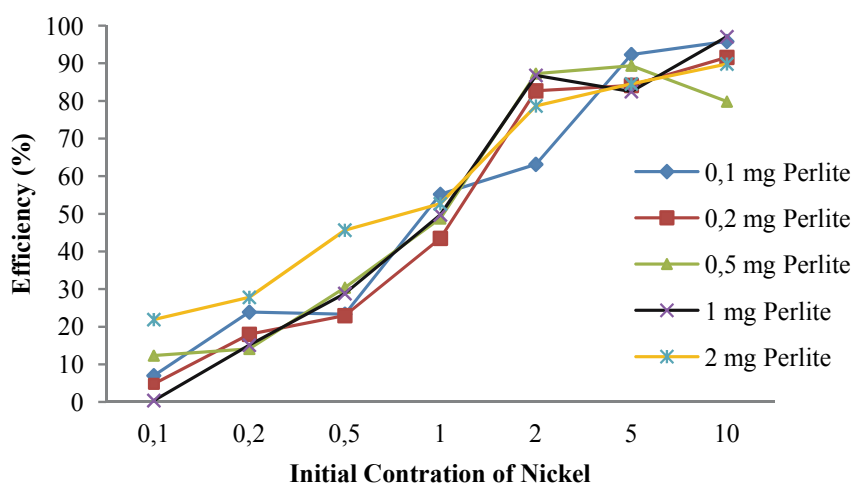

Fig. 2. Adsorbent efficiency figures showing variation based on 5 minutes' contact time

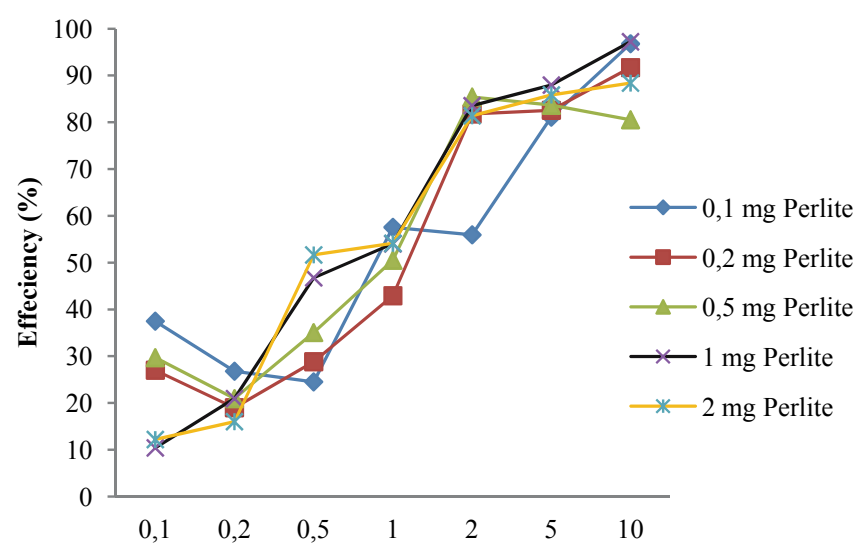

Fig. 4. Adsorbent efficiency figures showing variation based on 20 minutes' contact time were $0.1 \mathrm{mg} \mathrm{Ni} / \mathrm{L}, 0.2 \mathrm{mg} \mathrm{Ni} / \mathrm{L}-0.5 \mathrm{mg} \mathrm{Ni} / \mathrm{L}-1.0 \mathrm{mg} \mathrm{Ni} / \mathrm{L}$ $-5 \mathrm{mg} \mathrm{Ni} / \mathrm{L}-10 \mathrm{mg} \mathrm{Ni} / \mathrm{L}$. Each input concentration was shaken for 5-10-20-30 minutes. As a result of these experiments, the following figures and results were obtained. As can be seen in Figures 2, 3, 4 and 5, the adsorption efficiency of perlite was increased by escalating the amount of initial concentration. It can be seen from Figure 2 and Figure 5 that although the amount of adsorbent changed, each initial concentration and adsorption efficiency did not change. In addition, the efficiency of the adsorption was not affected by the contact time.

As can be seen from Figure 2, in the $0.1 \mathrm{mg} \mathrm{Ni} / \mathrm{L}$ initial concentration the amount of adsorbent does not make significant diffirence in the percentage of efficiency for 5 minutes' contact time. Even with the low amounts of adsorbent and high initial concentration of nickel, the highest efficiency rate is obtained.

It can be seen that, with regard to the $0.1 \mathrm{mg} \mathrm{Ni} / \mathrm{L}$ initial concentration, the amount of adsorbent is significantly different in terms of the percentage of efficiency for 10 minutes' contact time compared with 5 minutes' contact time. Figure 3 shows a $30 \%$ efficiency difference between the $0.1 \mathrm{mg}$ perlite and the $2 \mathrm{mg}$ perlite adsorbents.

As can be seen from Figure 4, the increase in contact time has a greater impact, particularly for low amounts of initial concentrations.

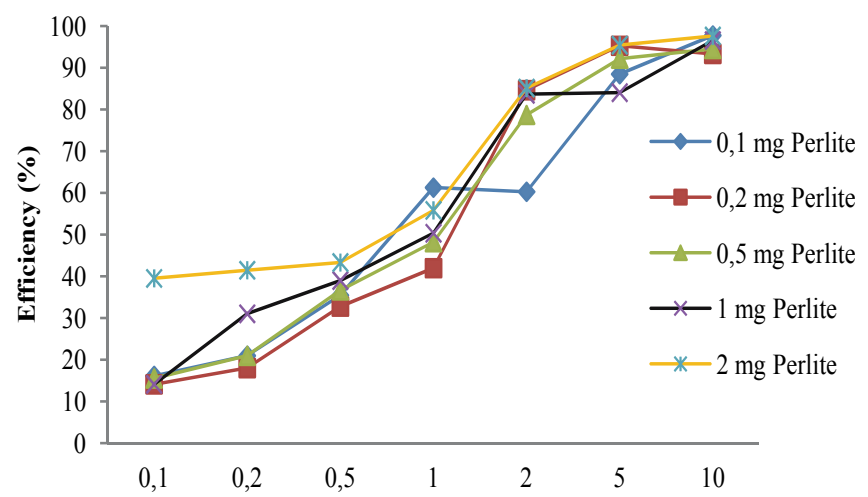

Fig. 3. Efficiency adsorbent figure showing variation in terms of 10 minutes' contact time

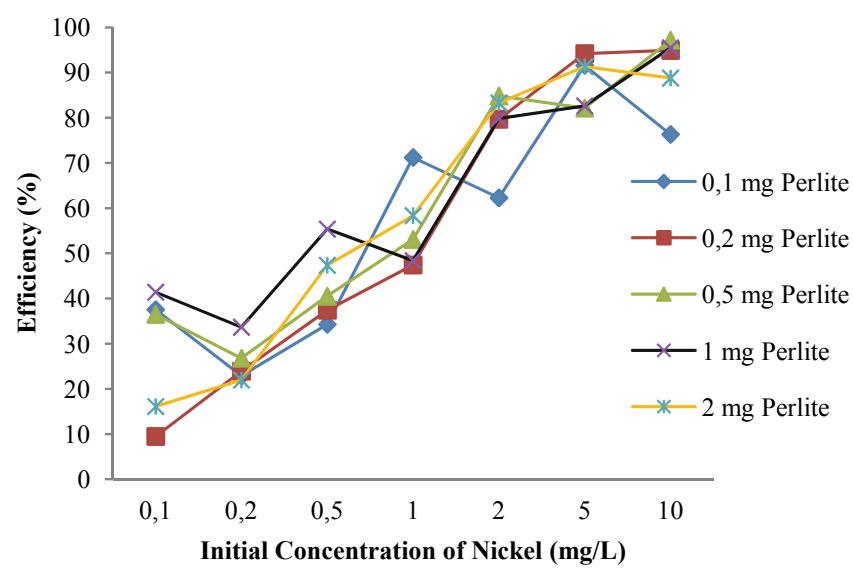

Fig. 5. Adsorbent efficiency figures showing variation based on 30 minutes' contact time 
By the time it reaches 30 minutes, not just in terms of low amounts of initial concentrations, the contact time has also an increasing impact on efficiency rates, for even high amounts of initial concentrations.

\section{Optimum ANN Architecture}

Once the iteration process achieves a result, the connection weights obtain and store the current information in the tests used during the training process. When a new input group is introduced to the network, an output group is obtained with the help of learned and stored feed-forward information in the connection forces. Therefore, ANN studies are formed by taking the input value as 3 , the output value as 1 , and the hidden layer values being processed as 3, 7, 12, 17 and 25, as can be seen in Figure 6. As is the case in a related ASCE study (ASCE, 2000), the sigmoid function is applied as the transfer function. A back propagation algorithm is also used as a generalized delta rule for ANN training.

\section{Conclusions}

ANN architecture gives the best results in terms of those obtained by trial and error. The trials for determination of the ANN architecture are given in Table 3. MSE and $\mathrm{R}^{2}$ performance values are used to determine the optimum ANN architecture. In this study, after various trials, several neurons

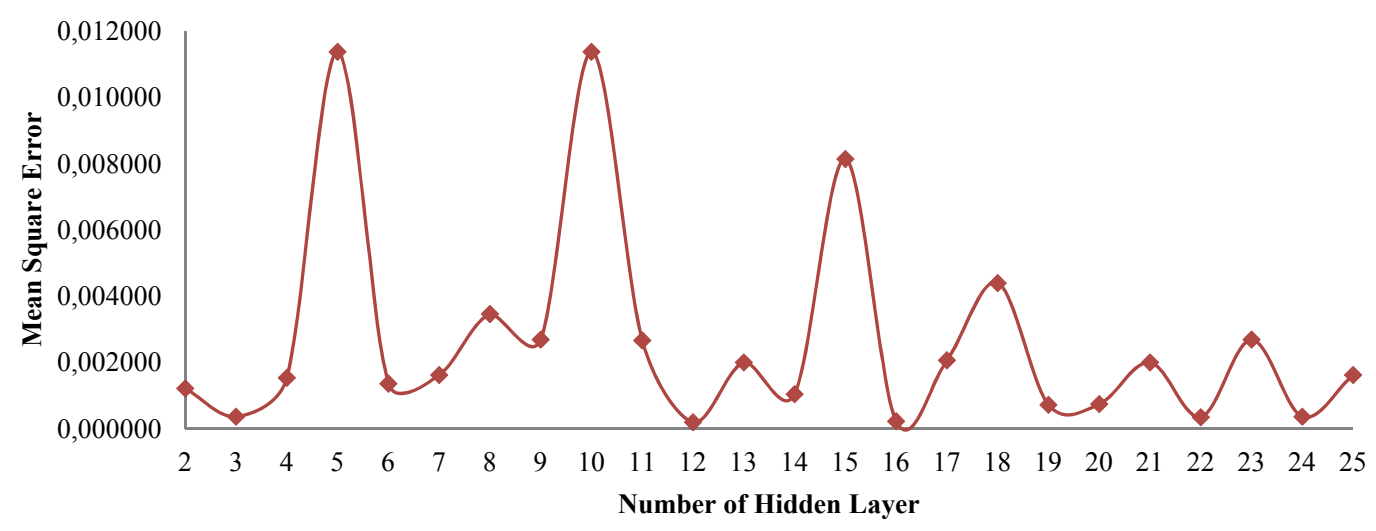

Fig. 6. Mean Square Error (MSE) values depending on the number of hidden layers
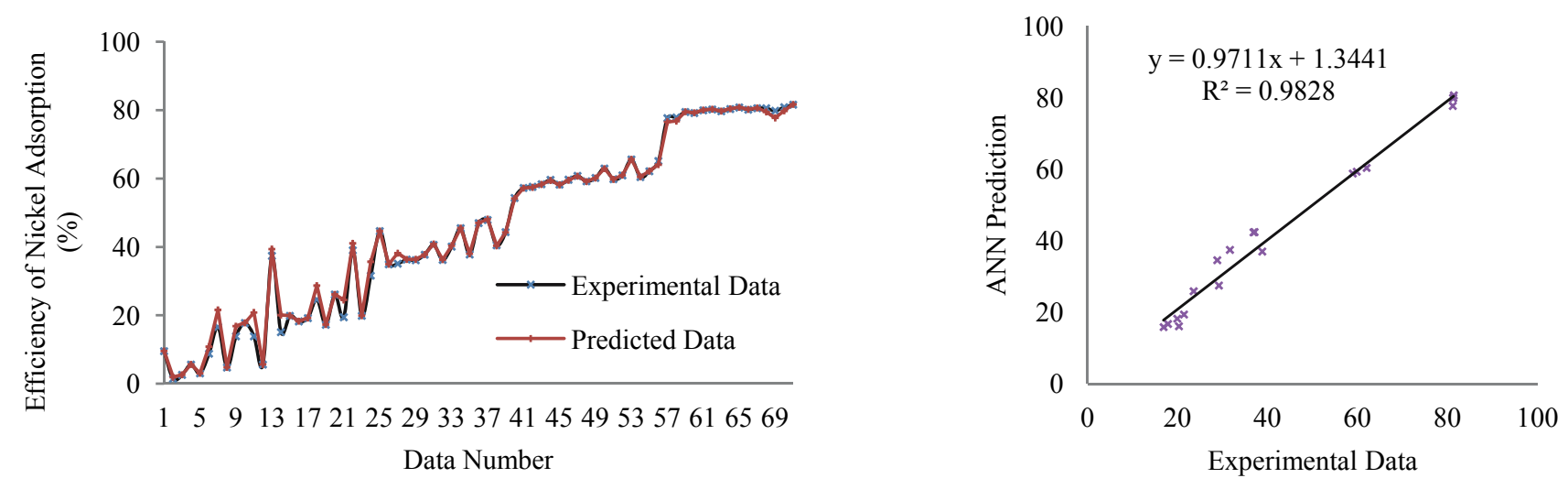

Fig. 7. Training data with ANN 3-12-1 efficiencies
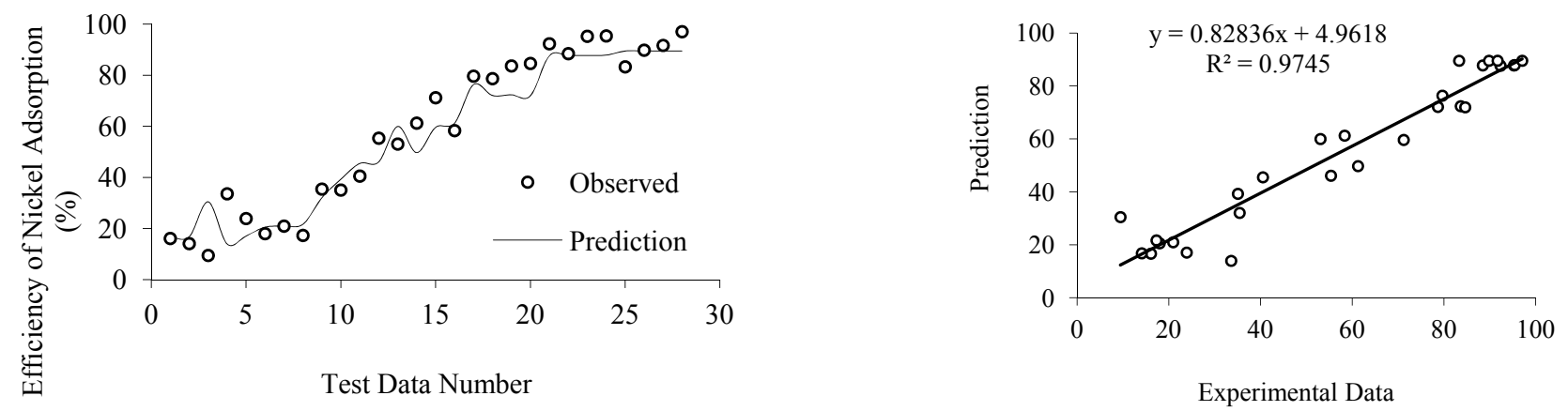

Fig. 8. Test data with ANN-3-12-1 efficiencies 
in the hidden layers were obtained from a set of test values. As seen in Table 3, the optimum test set value is the ANN (3-12-1) architecture.

The impact of all the ANN architectures were also calculated by comparing the predicted values with the experimental data by a test evaluation of the Mean Square Error (MSE) and Coefficient Determination $\left(\mathrm{R}^{2}\right)$. In this study, the prediction of nickel adsorption with a perlite adsorbent can be used to estimate the adsorption efficiency with an ANN by using experimental data. Wastewater polluted with nickel is created and the estimation ability of the prediction is tested. In Figures 2, 3, 4 and 5 perlite treatment in low concentrations of Nickel (II) wastewater does not give good results. When the contact time is taken into consideration, lower efficiency is obtained for 5 minutes' contact time as well as low initial concentrations. By increasing the contact time, the highest efficiency rates are obtained in terms of both low and high initial concentrations. Nickel (II) adsorption efficiency in wastewater with a high concentration is about $80-90 \%$ for all contact times. Based on these results, the optimum ANN architecture is found using a trial and error method to be ANN (3-12-1) (Table 3). The determination coefficient is 0.9445 in the ANN. Determining the data experimentally is both costly and time consuming.

As a result, nickel adsorption estimation can be done using the ANN developed in this study, when the nickel concentration of the wastewater, contact time and the amount of adsorbent are known, according to a Mean Square Error (MSE) of 1.9110 in Table 3, and a Coefficient Determination $\left(\mathrm{R}^{2}\right)$ of 0.9443 in Figure 9. Experimental data and ANN predictions were interrelated in the training, test and validation data in Figures 7,8 and 9. It is clear that the ANN prediction data are close to the experimental data in Figure 10. Thus, both the costs and the required time for the necessary experiments can be minimized.
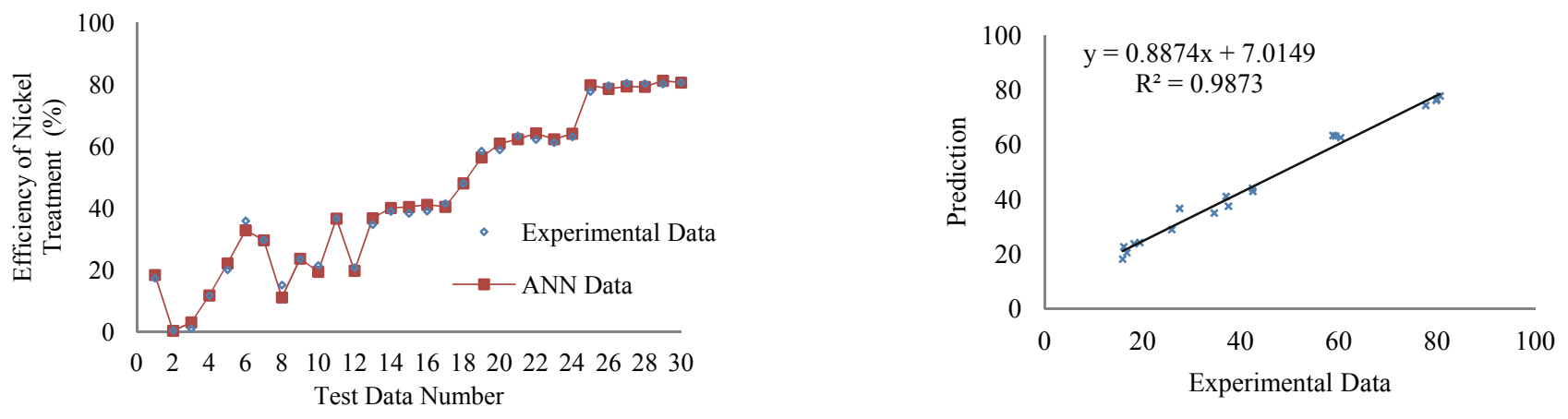

Fig. 9. Validation data with ANN-3-12-1 efficiencies

Table 3. Determination of the optimal ANN architecture

\begin{tabular}{|c|c|c|c|}
\hline $\begin{array}{c}\text { ANN architecture } \\
\text { (Neuron number in the layers) }\end{array}$ & $\begin{array}{c}\text { Number of iterations } \\
(\text { Epoch })\end{array}$ & $\begin{array}{c}\text { Coefficient Determination } \\
\left(\mathrm{R}^{2}\right)\end{array}$ & $\begin{array}{c}\text { Mean Square Error } \\
(\mathrm{MSE})\end{array}$ \\
\hline ANN $(3,12,1)$ & 1000 & 0.9445 & 1.9110 \\
\hline ANN $(3,3,1)$ & 1000 & 0.996 & 3.6233 \\
\hline ANN $(3,7,1)$ & 1000 & 0.987 & 16.576 \\
\hline ANN $(3,17,1)$ & 1000 & 0.972 & 21.154 \\
\hline ANN $(3,25,1)$ & 1000 & 0.997 & 7.551 \\
\hline
\end{tabular}

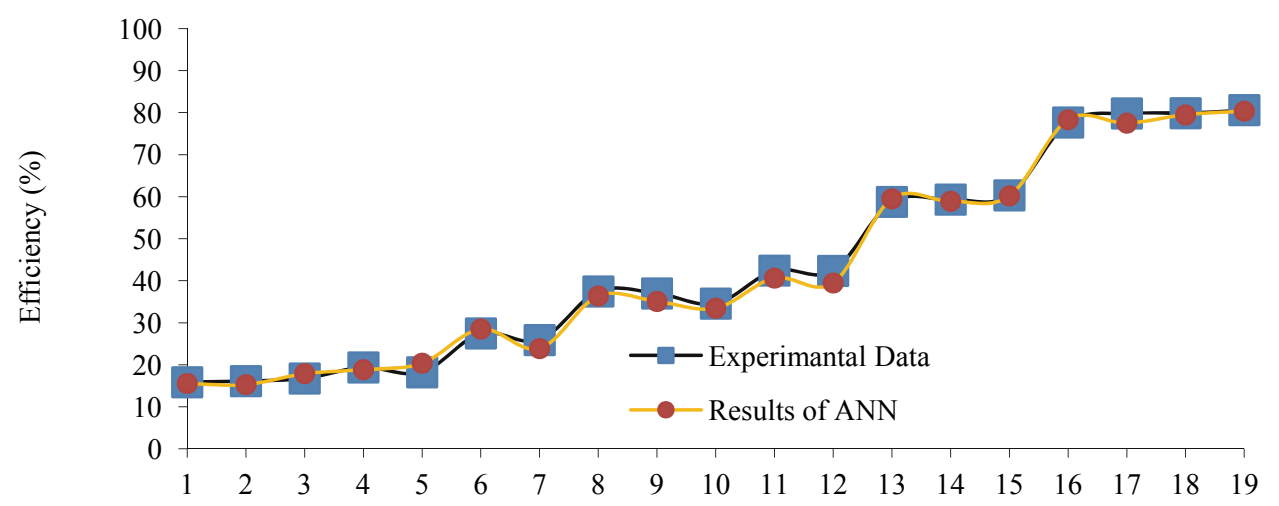

Fig. 10. Comparison between ANN and Experimental Data (3-12-1 ANN Architect) 


\section{References}

Alkan, M. \& Doğan, M. (2001). Adsorption of Copper(II) onto Perlite, Journal of Colloid and Interface Science, 243, pp. 280-291.

ASCE, 2000, Artificial neural networks in hydrology. I: Preliminary concepts, Journal of Hydrologic Engineering, 5(2), pp. 115-123, ASCE Task Committee on Application of Artificial Neural Networks in Hydrology.

Bui, H.M., Duong, H.T.G. \& Nguyen, C.D. (2016). Applying an artificial neural network to predict coagulation capacity of reactive dying wastewater by chitosan, Polish Journal of Environmental Studies, 25, 2, pp. 545-555.

Erdoğan, S., Önal, Y., Akmil-Basar, C. \& Bilmez-Erdemoglu, S. (2005). Optimization of Nickel adsorption from aqueous solution by using activated carbon prepared from waste apricot by chemical activation, Applied Surface Science, 252, pp. 1324-1331.

García-Vaquero, N., Lee, E., Jiménez Castañeda, R., Cho, J. \& LópezRamírez, J.A. (2014). Comparison of drinking water pollutant removal using a nanofiltration pilot plant powered by renewable energy and a conventional treatment facility, Desalination, 347, pp. 94-102.

Hagan, M.T., Demuth, H.B. \& Beal, M.H. (2003). Neutral network design, PWS, Beston 2003.

Hamed, M.M., Khalafallah, M.G. \& Hassanien, E.A. (2004). Prediction of wastewater treatment plant performance using artificial neural networks, Environmental Modeling \& Software, 19, pp. 919-928.

Jiang, S., Huang, L., Nguyen, T.A., Ok, Y.S., Rudolph, V., Yang, H. \& Zhang, D. (2016). Copper and zinc adsorption by softwood and hardwood biochars under elevated sulphate-induced salinity and acidic pH conditions, Chemosphere, 142, pp. 64-71.
Malkoc, E. \& Nuhoğlu, Y. (2006). Removal of Ni(II) ions from aqueous solutions using waste of tea factory: Adsorption on a fixed-bed column, Journal of Hazardous Materials, B135, pp. 328-336.

Moradi, M., Fazizadehdavil, M., Pirsaheb, M., Mansouri, Y., Khosravi, T. \& Sharafi, K. (2016), Response surface methodology (RSM) and its application for optimization of ammonium ions removal from aqueous solutions by pumice as a natural and low cost adsorbent, Archives of Environmental Protection, 42, 2, pp. 33-43.

Nadaroğlu, H., Kalkan, E. \& Çelebi, N. (2014). Removal of copper from aqueous solutions by using micritic limestone, Carpathian Journal of Earth and Environmental Sciences, 9, 1, pp. 69-80.

Podder, M.S. \& Majumder, C.B. (2016). The use of artificial neural network for modelling of phycoremediation of toxic elements $\mathrm{As}(\mathrm{III})$ and $\mathrm{As}(\mathrm{V})$ from wastewater using Botryococcus braunii, Spectrochimica Acta Part A: Molecular and Biomolecular Spectroscopy, 155, pp. 130-145.

Prakash, N., Manikandan, S.A., Govindarajan, L. \& Vijayagopal, V. (2008). Prediction of Biosorption efficiency for the removal of copper (II) using artificial neural networks, Journal of Hazardous Materials, 152, pp. 1268-1275.

Ranade, V.V. \& Bhandari, V.M. (2014). Industrial Wastewater Treatment, Recycling, and Reuse, Elsevier Ltd, ISBN: 978-0-08-099968-5.

Sarkar, A. \& Pandey, P. (2015). River Water Quality Modelling Using Artificial Neural Network Technique, Aquatic Procedia, 4, pp. 1070-1077.

Yesilnacar, M.I. \& Sahinkaya, E. (2012). Artificial neural network prediction of sulfate and SAR in an unconfined aquifer in southeastern Turkey, Environmental Earth Sciences, 67, 4, pp. 1111-1119.

Yesilnacar, M.I., Sahinkaya, E., Naz, M. \& Ozkaya, B. (2008). Neural network prediction of nitrate in groundwater of Harran Plain, Turkey, Environmental Geology, 56, 1, pp. 19-25. 